\title{
PERSPECTIVAS LABORALES EN EL TURISMO EN MÉXICO POST-COVID 19
}

\section{Labor prospects in tourism in México post-Covid 19}

\section{Carlos Hugo Milán García}

Docente en la Facultad de Turismo y Gastronomía

en la Universidad Autónoma del Estado de México.

(UAMéx). ORCID: 0000-0001-5194-5731

Correo-e: chmillang@uaemex.mx

\section{Gloria Georgina Icaza Castro}

Docente en la Facultad de Turismo y Gastronomía en

la (UAMéx). ORCID: 0000000190642872

Correo-e: ggicazac@uaemex.mx

\section{Mónica Del Valle Pérez}

Docente en la Facultad de Turismo y Gastronomía en

la (UAMéx). ORCID: 0000-0002-1512-3885

Correo-e: mdelvallep@uaemex.mx

Recibido: 21/02/2021 - Aprobado: 07/05/2021

Cómo citar: Millán-García, C. H., Icaza Castro, G. G., \& Del Valle Pérez, M. (2021). Perspectivas laborales en el turismo en México post-Covid 19. Ciencia y Sociedad, 46(2), 85-106. DOI: https://doi.org/10.22206/cys.2021.v46i2.pp85-106

\section{Resumen}

Se ha señalado la precariedad laboral y la necesidad de la profesionalización de la fuerza laboral como parte de los problemas que demandan atención en la industria turística, mismas que se agravan ante la contingencia sanitaria ocasionada por el Covid-19 por lo que se requiere colocar en la mesa de discusión, comenzando por su reconocimiento.

El presente trabajo persigue como objetivo analizar las condiciones laborales presentes en la industria turística de México y la situación desde la que enfrentará su recuperación en cuestiones contractuales, después de la contingencia sanitaria.

Para lograr el objetivo, se retoma el enfoque teórico del turismo desde la perspectiva económica, así como la literatura que expone las formas de precarización específica del turismo y se compara con la realidad presente entre quienes laboraban en la actividad al inicio de la contingencia.

\begin{abstract}
Job insecurity and the need for the professionalization of the workforce have been pointed out as part of the pending issues to be addressed in the tourism industry, situations that, in the face of the health contingency caused by Covid-19, would be accentuated for those who work in the tourism.

The present work aims to analyze the working conditions present in the Mexican tourism industry and the situation from which it will face its recovery in contractual matters, after the health contingency.

To achieve the objective, the perspective of tourism as economic activity is retaken, as well as the literature that exposes the forms of specific precariousness of tourism and is compared with the present reality among those who worked in the activity at the beginning of the contingency.
\end{abstract}


Para ello se propone un enfoque positivista, empleando un cuestionario que permitió recopilar información de empleados turísticos en México al inicio de la contingencia, en un momento crítico, cuando aún no se conocía la duración que tendría. Se encontró que, aunque el actual marco legal conduce a su precarización, alrededor de la mitad tiene un trabajo estable, valorado así por el nivel de ingresos que percibe y regresaría prácticamente en las mismas condiciones, tan pronto se vaya recuperando la actividad, al tiempo que asume la presente contingencia como parte del riesgo, de la realidad a la que se enfrenta el turismo y la asumen como tal. Esto entre quienes han alcanzado la profesionalización mediante la especialización o formación específica y ocupan mandos medios o superiores; siendo contrario entre aquellos que no tienen una formación en turismo, o que recientemente se incorporaron a la actividad.

Palabras clave: turismo; empleo; Covid-19; precarización laboral; profesionalización

\section{Introducción}

El turismo es una actividad susceptible a muchos elementos que provocan una paralización de sus actividades, en ocasiones de manera inmediata. Tal es el caso que se vive con la contingencia sanitaria del Covid-19, similar en el riesgo de propagación, aunque distinta en impacto, a la que se vivió en el año 2009 con el virus de la influenza AH1N1. Un ejemplo más se encuentra en la proliferación del sargazo en 2019, que invadió el mar Caribe principalmente y que ahuyentó al turismo, y otros casos lo representan los huracanes, cuando sus efectos se producen en cercanía con los principales destinos turísticos del país, cada año durante la temporada.

La contingencia sanitaria originada por el virus Covid-19 centró la atención mundial en la temática de salud, como resulta indiscutible. Sin embargo, sus efectos en la economía debido a las medidas recomendadas de confinamiento para su mitigación, ha dado lugar a discusiones sobre una diversidad de temas dentro del mismo campo económico y en otros como el educativo y social, por citar.
A questionnaire was distributed among tourism employees in Mexico who occupied different levels. It was found that, although the current legal framework leads to their precariousness, around half have a stable job, valued thus by the level of income they receive and will return practically in the same conditions, as soon as the activity recovers, at the same time that assumes the present contingency as part of the risk, part of the reality that tourism faces and they assume as such. This is among those who have achieved professionalization through specialization or specific training and occupy middle or higher management; being the opposite among those who do not have a training in tourism, or who recently joined the activity.

Keywords: Tourism; employement; Covid-19; insecurity; professionalization

El presente artículo, desde un enfoque positivista y uno teórico del turismo, con base en una perspectiva económica, centra su atención en el empleo y propiamente en el empleo turístico como factor. Tiene como objetivo principal analizar las condiciones laborales a las que se enfrentará este sector al irse reactivando la actividad turística después de la contingencia sanitaria, conocer los grupos de la población que se ven más afectadas por la misma condición y proponer algunas alternativas que en el futuro ayuden a mitigar estos efectos.

Ante el panorama que se presentó por el COVID19, la Organización Mundial del Turismo OMT (UNWTO por sus siglas en inglés) hizo un llamado a los gobiernos, a las empresas y a la comunidad internacional en general para enfrentar la contingencia que calificó como 'desafío sin precedentes', sobre todo enfocadas a mantener el empleo y apoyar a las empresas más vulnerables (UNWTO, 2020), así como prepararse para la época post-contingencia, para 'el día después'.

A nivel global la OMT (UNWTO, 2020) estima que entre 100 y 120 millones de empleos turísticos 
se encuentran en riesgo de perderse, similar a la estimación del Consejo Mundial de Viajes y Turismo (WTTC, 2020) dependiendo de cómo se vayan modificando los patrones de apertura, las restricciones y el control de la pandemia en los países.

De acuerdo con el Instituto Nacional de Estadística y Geografía, INEGI (2020a) en el mes de abril de 2020 se reportó un total de 12 millones de personas económicamente activas en estado de suspensión temporal, sin percepción de ingresos y sin certeza de regresar con una relación laboral y una tasa de subocupación de $25.4 \%$, es decir, 11 millones de personas. Esto es, que dicha cantidad de personas tuvieron que suspender sus actividades y se quedaron sin recibir los ingresos correspondientes a la actividad económica que desempeńaban al inicio de la contingencia.

Los datos anteriores del INEGI corresponden a todas las actividades económicas en el país, pero para el turismo en México, el Consejo Nacional Empresarial Turístico (CNET) estima que las pérdidas alcanzarán en el presente año 1 billón 500 mil millones de pesos, una contracción de hasta $46 \%$ del PIB Turístico, lo que ocasionará que sea considerado como un año perdido y con un costo cercano a 1 millón de empleos perdidos (CNET, 2020).

En ese sentido, de acuerdo con el CNET, la recuperación turística para México será hasta 2024 (CNET, 2020), aunque al igual que las estimaciones de la OMT y del WTTC, dependerá de las condiciones como se vaya desarrollando y controlando la contingencia.

Los volúmenes de pérdidas por ingresos por concepto de turismo y la caída en la tendencia de visitantes internacionales que registra el país en los últimos años, tienen un impacto en el empleo turístico, que aunque se habla de él de manera general, no se detallan las condiciones que enfrentan quienes se dedican a este sector, al tiempo que pone al descubierto que las modificaciones a la Ley Federal de Trabajo (LFT) le son adversas y lo dejan a la deriva, evidenciando que los beneficios atribuidos a la actividad en términos económicos para la población son vulnerables.

De esta forma, en el marco de la contingencia sanitaria por Covid-19, para el logro del objetivo señalado y con la intención de identificar esas condiciones, se diseñó un cuestionario que recopiló información referente a las condiciones en las que se encontraba el personal que tiene el turismo como actividad económica, en función a su edad, sexo e industria de la que dependía. Posteriormente, se indaga sobre algunas características de su condición laboral como el puesto ocupado, antigüedad y tipo de contrato o de relación laboral. Por último, se pregunta sobre los efectos de las medidas de confinamiento en sus ingresos, en su relación laboral y sobre algunas medidas que ayuden a paliarlos en futuras situaciones que afecten al turismo.

\section{Marco Teórico-Referencial}

Para abordar la temática, se toma al turismo como actividad económica, de la cual se desprende el componente empleo y las características del mismo.

\section{Turismo como actividad económica}

El turismo es un gran aporte para la economía mundial, como se mostrará enseguida. Grandes economías emergentes, así como desarrolladas, dependen en gran parte del sector turístico.

La globalización, así como las relaciones entre los países han provocado que viajar sea cada vez una opción más frecuente. Es decir, el porcentaje de la población mundial que requiere de un visado tradicional para viajar a destinos extranjeros disminuyó del 75 \%, en el año 1980, al 53 \%, en 2018. Esto está provocando que cada vez más personas se desplacen entre los países de manera recurrente, incrementando los viajes de ocio de un $50 \%$, a un 
$56 \%$, de acuerdo con el informe de la Organización Mundial del Turismo (OMT, 2020).

El turismo ha mostrado ser generador de riqueza y empleo en aquellos países que más turistas acogen, lo que ha provocado que adquiera mayor importancia como actividad económica en las principales economías del mundo y en los países en desarrollo.

Lo anterior se refleja en el incremento de la inversión que los países destinan a la industria turística y aquella infraestructura que facilita su crecimiento, así como promover el atractivo de sus principales destinos turísticos a nivel global.

El turismo, en resumen, se ha convertido en un pilar fundamental para el crecimiento económico de los países, llegando a representar una gran cuantía en el porcentaje del producto interior bruto (PIB) mundial, como se ejemplifica a continuación.

De acuerdo con los últimos datos publicados por el Consejo Mundial de Viajes y Turismo (WTTC, por sus siglas en inglés), el sector turístico, con una representación del $10.4 \%$, supone uno de los sectores con mayor contribución al PIB mundial. Así mismo, con 8.8 billones de dólares, el sector turístico se posiciona como uno de los sectores con mayor crecimiento del mundo, siendo superado únicamente por servicios tecnológicos y manufactureros.

A continuación, se muestran los diez principales países por volumen de llegadas internacionales, de acuerdo con datos de la OMT.

Gráfica 1. Top 10 de paises receptores de turismo internacional

\section{Llegadas Internacionales en millones de personas}

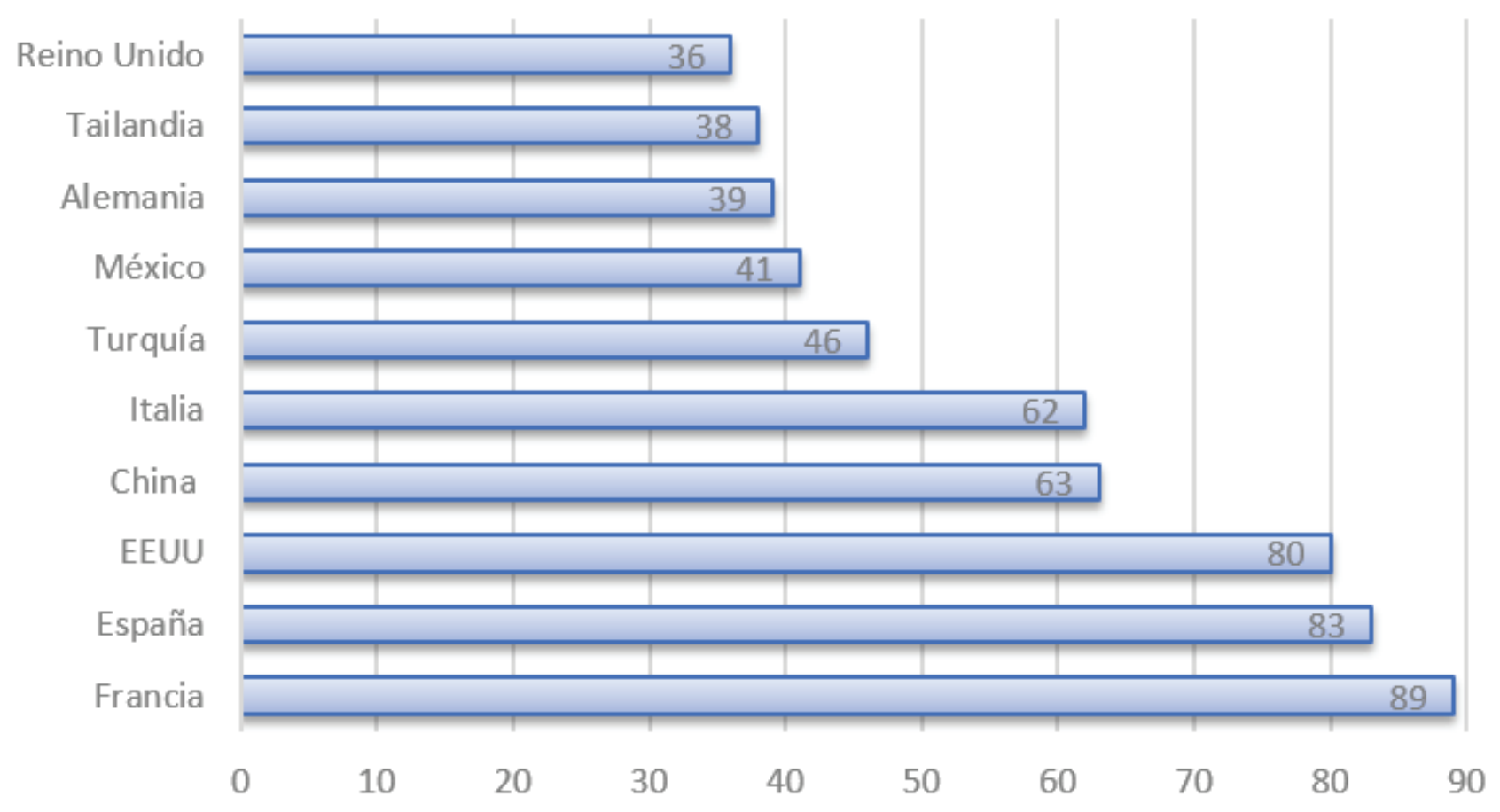

Nota: fuente OMT (2020). 
Los diez países de este ranking concentran el $40 \%$ del turismo de todo el mundo. Sin embargo, también se puede identificar una diferenciación de al menos tres 'subgrupos'. Aquellos que buscan los primeros tres lugares (Francia, España y EEUU), aquellos que se ubican en el cuarto y quinto lugar (Italia y China) y los que tratan de liderar el tercer escalón entre los lugares sexto y décimo.

Es decir, si bien son diez países que lideran en captación de turistas, sus niveles se sitúan en realidades distintas.
Más aun, cuando se habla de los ingresos generados por concepto de turismo, el ranking cambia de orden y en algunos casos de participantes. En la gráfica siguiente se muestra la captación de estos ingresos, donde no figura dentro del top 10 ningún país latinoamericano. Se incluye el caso de México al ser el más alto, sin embargo, ocupa la posición 16 entre los países que mayores ingresos obtiene del turismo.

Gráfica 2. Top 10 de países en captación de ingresos por turismo

\section{Ingresos en millones de dólares por turismo}

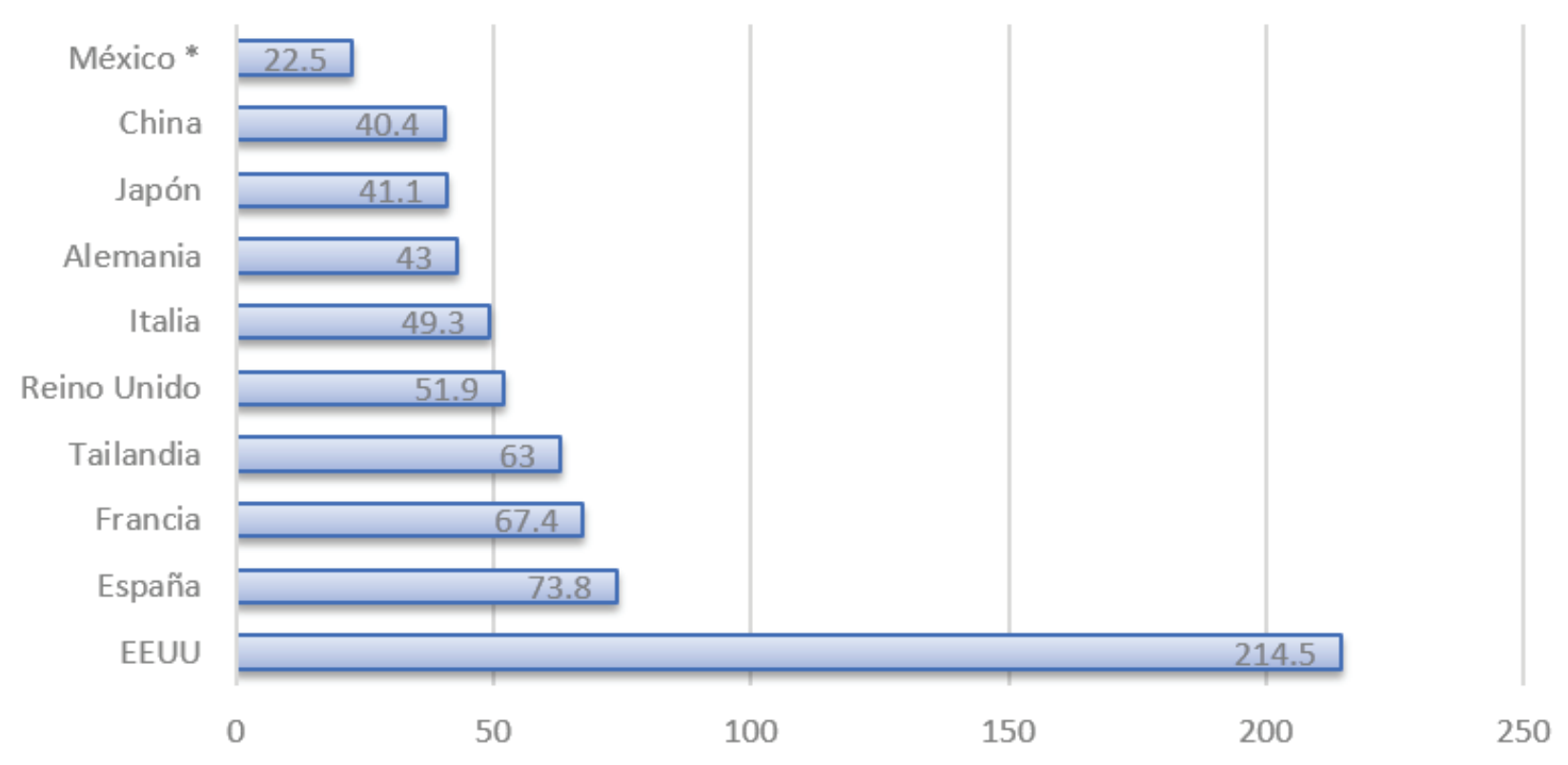

Nota: fuente Sectur (2018). * Ocupa la posición 16 a nivel global, se incluye como el mejor país latinoamericano.

En los últimos años, se ha visto al turismo ganar un fuerte peso en las economías, tal es el caso del seguimiento puntual que se le da a los dos indicadores mostrados en las gráficas por parte de los países y de organizaciones, pues se está convirtiendo en uno de los motores de crecimiento más rentables para la economía global, por lo que el liderazgo en el sector es disputado por todos los principales países, que luchan cada año para atraer cada vez más turistas a sus territorios. 
De acuerdo con el informe de la OMT "Panorama del turismo internacional”, el turismo genera más de 5.000 millones de dólares al día. A su vez, la suma de los ingresos por turismo extranjero a nivel mundial, así como el costo del transporte de pasajeros en el mundo generó 1,7 billones de dólares el año pasado. Por último, durante el 2018 se registraron 1.400 millones de llegadas de viajeros internacionales en todo el mundo (OMT, 2020).

El crecimiento de las llegadas de turistas internacionales y de los ingresos sigue adelantando al de la economía mundial, y tanto las economías emergentes como las avanzadas se han beneficiado del aumento de los ingresos provenientes del turismo. Para el 2019 de acuerdo a la OMT, se reportaba que por séptimo año consecutivo, las exportaciones turísticas crecieron más deprisa que las exportaciones de mercancías, lo cual redujo en muchos países el déficit comercial (OMT, 2020).

De acuerdo con el Secretario General de la OMT-UNWTO Pololikashvili, este crecimiento conlleva:

una mayor responsabilidad a la hora de garantizar una gestión efectiva de los destinos que minimice cualquier efecto adverso del turismo. Gestionar el turismo de manera sostenible y en beneficio de todos es hoy más importante que nunca. Necesitamos crecer más en valor y no solo en volumen. La digitalización, la innovación, una mayor accesibilidad y ciertos cambios sociales seguirán moldeando el sector, y tanto los destinos como las empresas tendrán que adaptarse para seguir siendo competitivos (UNWTO, 2019, p. 2).

En países de la OCDE, como España, representa cerca del $15 \%$ de su PIB; otros países europeos como Francia o Portugal, representa, respectivamente, el 7,3 \% y el 13,7 \% del PIB. En otros países de América Latina, como México, por ejemplo, ya supone el 8,7 \% del PIB en el país. En general, un sector turístico que, a fecha de 2018, suponía el 4,1 \% del PIB de los países miembros de la OCDE, así como el $6 \%$ del empleo en los mismos. (INEGI, 2019).

\section{Generador de empleo}

Como cabe esperar, el crecimiento económico se compone de muchos agregados que, desagregados y puestos en relevancia, ponen de manifiesto un mayor atractivo para el sector turístico.

De acuerdo con los datos que ofrece la lectura del informe realizado por la WTTC, el turismo, al año 2018, empleaba a 319 millones de personas, esperando que esta cifra se multiplique hasta los 421 millones de ocupados, según estimaciones para 2029 (WTTC, 2020). Es decir, el turismo no solo es un motor de crecimiento económico, sino que ese motor impulsa a su vez el propio empleo, ya que, por detrás de la industria manufacturera, es el que mejores cifras presenta en la creación de empleo.

En los últimos cinco años, uno de cada cinco empleos que se han generado el mundo han estado relacionados de forma directa con el turismo. Esto ha llevado a que uno de cada diez trabajadores en el mundo se encuentren empleados en esta industria (Datatur-Sectur, 2020).

Además del número de empleos generado, es considerado también en su forma inclusiva y con oportunidades para ambos géneros; así como generador de empleo para los más jóvenes. De acuerdo con el informe 'Perspectivas internacionales sobre la mujer y el trabajo en hoteles, restauración y turismo' citado por Hosteltur (2018), las mujeres representan una participación del 55,5\%—a escala global— de la industria turística.

En ese mismo sentido, el informe reporta que, con los niveles de crecimiento de empleo mostrado, se espera siga generándolo de forma exponencial durante los próximos años. Una industria que, ante 
los resultados obtenidos y su irrupción en el crecimiento económico mundial, está ganando cada vez más peso en las economías, frente al deterioro de otros sectores y la ralentización de la economía global. Una realidad que, sin embargo, es susceptible de riesgos ocasionados por el clima, la seguridad, o la salud como en la actualidad.

\section{Turismo en México}

El turismo es una actividad económica dinámica, capaz de mantener un ritmo de crecimiento favorable, como se ha mencionado; se constata en la tendencia de crecimiento global al pasar de 997 millones de turistas internacionales en 2011 hasta alcanzar 1462 millones en el año 2019 (OMT, 2020) y 45 millones de viajeros internacionales en el año 2019 para México (Sectur, 2020), a pesar de que se puedan presentar condiciones adversas en el entorno nacional o internacional, como se había visto hasta antes de la actual contingencia.

Ese crecimiento que ha experimentado el turismo nacional ha producido una diversidad de la oferta turística, misma que ha sido agrupada en Turismo Cultural, Turismo de Reuniones, Turismo Deportivo, Turismo de Salud y Bienestar, Turismo de Sol y Playa, Turismo de Naturaleza, Turismo Gastronómico, con un alrededor de 40 distintas subdivisiones de acuerdo con el Atlas Turístico de México (Sectur-Datatur, 2020).

Hoy en día, el volumen de ingresos generados por turismo para México compite con las exportaciones de petróleo, productos alimentarios, la industria automotriz, con los ingresos por remesas, con variaciones que provocan que ocupe cada año uno de los tres principales lugares. Para el año 2019, los ingresos por turismo superaron los 24 mil millones de dólares (Sectur, 2020), resultado de eso más de 45 millones de visitantes internacionales que llegaron a México y que lo llegaron a colocar como el sexto país en importancia en ese tema.
El dato anterior deja un saldo positivo en la balanza comercial de 14 mil 715 millones de dólares y representa un gasto promedio del turista de 496 dólares.

La actividad turística, desde la perspectiva económica para el país, representa a su vez la generación de 4.4 millones de empleos, reflejando una tendencia positiva en los últimos años, como se aprecia en la tabla 1 y la gráfica 1 .

Tabla 1. Empleo turístico al 4to trimestre de cada año
Año

2011

2012

2013

2014

2015

2016

2017

2018

2019

\section{Empleo}

$3,409,804$

$3,536,686$

$3,628,195$

$3,640,970$

$3,803,442$

$3,951,887$

$4,095,282$

$4,187,463$

$4,438,496$
Nota: elaboración propia a partir de INEGI, (2020b).

La tendencia positiva de la generación de empleo se puede apreciar en la gráfica 3 . 
Gráfica 3. Crecimiento del empleo en el turismo

\section{Empleo}

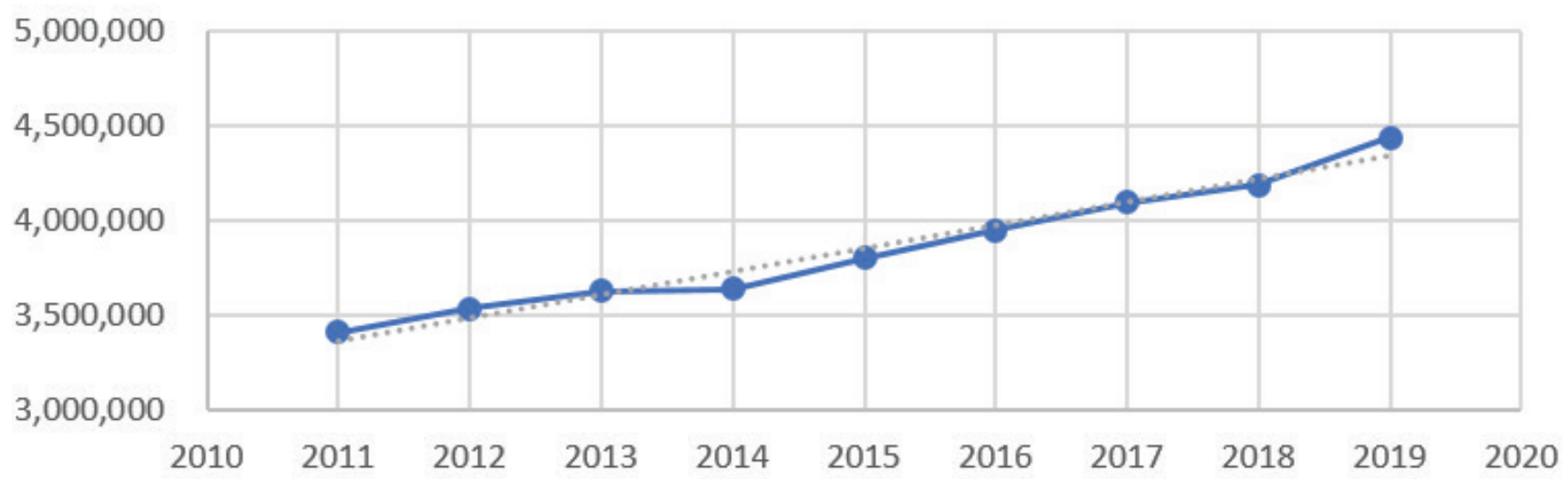

Nota: elaboración propia a partir de INEGI, (2020b).

México cuenta con 23,200 establecimientos de hospedaje y 830 mil cuartos de hotel, siendo la principal industria en la generación de empleo, resultado de la ocupación por parte de 129 millones de turistas de esos cuartos de hotel, sosteniendo una ocupación promedio nacional del $61 \%$ (Sectur, 2020).

De acuerdo con la Secretaría de Turismo Federal (Sectur) el principal mercado turístico de México es el proveniente de Estados Unidos. Solo el mercado de Norteamérica equivale a casi el $70 \%$ del total de turistas internacionales recibidos (Sectur, 2020).

En línea con la información más reciente de la actividad turística en México, como consecuencia de la contingencia sanitaria, se tuvo una caída de $22.4 \%$ en la llegada de visitantes internacionales en el periodo de enero-abril y de $32 \%$ en los ingresos por concepto de turismo (Sectur, 2020). Estos resultados reflejan, en parte, el rompimiento de la cadena alcista que se registraba en todos los indicadores turísticos de relevancia, de los cuales se ha dado cuenta en los párrafos anteriores. Parcialmente, pues si bien la llamada de alerta se dio desde finales del año 2019, en México no es sino hasta marzo cuando se hace el llamado al cierre de actividades no esenciales.

\section{Características del empleo turístico en México}

Uno de los argumentos que se emplean para destacar la importancia de la actividad turística es la generación de empleo, sobre todo para sectores considerados vulnerables: mujeres y jóvenes. Sin embargo, si bien es cierta esa afirmación, la pretensión de este apartado es describir dos de las principales características de esos empleos: flexibilización y precariedad vía subcontratación.

$\mathrm{Al}$ respecto y en la presente contingencia, Palafox-Muñoz y Rubí-González (2020) aseguran que ha quedado expuesta su fragilidad laboral frente a los servicios de salud y el acceso a la seguridad social, con la incertidumbre sobre la evolución que pueda tener, si las medidas sanitarias se mantendrán, habilitando la posibilidad de recepción del turismo (Montiel-Flores, 2020).

\section{Flexibilización}

Rubí-González \& Palafox-Muñoz (2017) sintetizan las implicaciones y formas en que se manifiesta la flexibilización laboral en el turismo, que van de la numérica externa, referida a la facilidad para contra- 
tación y despidos; numérica interna, aquella que permite ajustar horarios a los trabajadores para minimizar el pago de horas extra o alargar las jornadas de trabajo; funcional, en cuanto a que la contratación no específica permite a la empresa disponer de la fuerza de trabajo y emplearla en cualquier tarea genérica; salarial, consistente en establecer un ingreso mínimo y trasladar el salario hacia el cliente mediante el pago de propinas; y estratégica, que resulta de las anteriores para evadir su responsabilidad en seguridad social y fiscal.

En ese mismo sentido Rubio (2017) sumando al debate teórico en torno a la precariedad laboral identifica cuatro principales formas de ella: temporalidad, vulnerabilidad, insuficiencia salarial y desprotección laboral.

Temporal para referirse a la inseguridad en cuanto a la continuidad de su trabajo; vulnerabilidad en las condiciones físicas, mentales en las que desempeña su trabajo; insuficiencia salarial para referirse a que sus ingresos no le alcanzan para satisfacer sus necesidades básicas; y desprotección laboral para referirse a la ausencia o limitación de sus prestaciones y protección social.

De acuerdo con Sánchez y Olivarría (2016), la flexibilidad laboral comienza en los años ochenta como resultado de las bajas tasas de crecimiento económico, tanto en países industrializados como en los llamados en vías de desarrollo para romper con la rigidez impuesta, hasta entonces, por los mercados laborales.

Esta rigidez, desde la perspectiva empresarial turística, lleva al encarecimiento por las condiciones establecidas en cantidad (duración de las jornadas laborales continuas vs. picos de atención de clientes, duración de las relaciones laborales y pago de periodos de bajo volumen de ventas, costos de contratación y despidos implícitos por la duración de los contratos), como en calidad (cualificación de la mano de obra), sobre todo cuando se trata de turismo y su estacionalidad.

Si bien, la flexibilización laboral no es nueva, como lo señalan Méndez et al. (2013), por lo que la reforma solo legitimó la práctica persistente en la realidad.

Cañada e Izcara (2021) reconocen que las posturas en torno a las relaciones laborales se dirigen en dos sentidos: el primero entre quienes lo ligan con el desarrollo empresarial competitivo; y en el segundo, quienes ven en ello nuevas formas de explotación, control y precarización del trabajo.

Igualmente se identifica en su estudio, que las personas que sufren la precarización laboral son aquellas que ofrecen mano de obra no calificada, en procesos mecanizados y fácilmente sustituibles, como se hace notar en el presente y personas que se encuentran en un "proceso de transición" en busca del trabajo para el cual se han preparado. Sin que ello signifique menosprecio por su persona o por sus derechos.

En el Plan Nacional de Desarrollo 2013-2018 se planteaba la necesidad de formalizar la flexibilidad laboral, en el apartado correspondiente al empleo, que, si bien ya se contemplaba en la adición de los artículos 15A, 15B, 15C, 15D (con relación a la subcontratación) y el 35 y $39 \mathrm{~F}$ (con relación al trabajo discontinuo y temporal) la Ley Federal de Trabajo en el año 2012 (Cámara de Diputados, 2019), fue impulsada con la finalidad de generar más empleos (sin reparar en las condiciones) con un notorio interés de "reducir los costos para las empresas al emplear a trabajadores formales..." (Presidencia de la República, 2013).

Las reformas a la LFT han logrado su objetivo en cuanto a flexibilización al permitir la división de una jornada laboral ajustándose a los horarios pico de los servicios turísticos; hace legal la contratación temporal (que ya existía) contabilizando para el empleado solo los días de la semana efectivamente trabajados, logrando con ello reducir las primas por 
descanso semanal, vacaciones, antigüedad, aguinaldo, entre otros derechos.

Como consecuencia para las empresas representa un menor costo la contratación y el despido del personal, pues a ello se han sumado los periodos de prueba durante los cuales, si bien el empleado goza de protección social, al término de los tres meses puede ser declarado como no competente para el puesto si que tenga derecho a indemnización alguna.
En el turismo, estas últimas condiciones se ajustan a la temporalidad de la actividad con lo que las esperanzas para la población de garantizarse un empleo estable disminuyen.

El objetivo de incrementar el empleo también se ha logrado, pues de la mano del crecimiento de la actividad turística y los ingresos que genera, también se ha incrementado el empleo en los últimos años como se puede ver en la gráfica 4 .

Gráfica 4. Resultados de empleo turístico hasta el cuarto trimestre de 2019

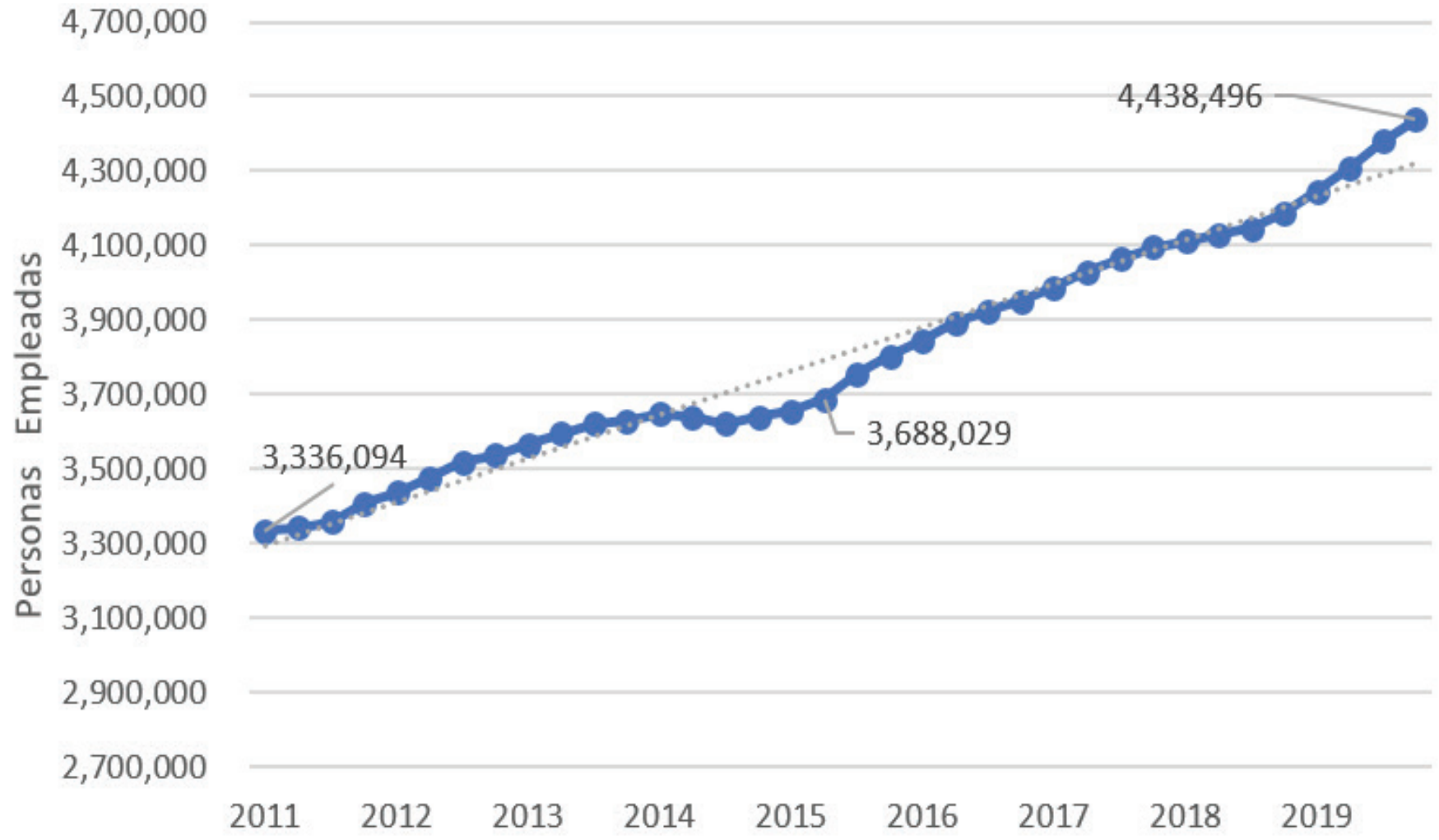

Nota: elaboración propia a partir de los datos de la Encuesta Nacional de Empleo de INEGI (2020).

En la gráfica se aprecia que el empleo ha pasado de mas de 3 millones 300 mil en el año 2011 hasta llegar a más de 4.4 millones en el 2019. Si bien se aprecia una caída en los años 2014 y 2015 se recupera en los siguientes. Así mismo, la línea de tendencia marca una pendiente positiva constante. 


\section{Precarización vía subcontratación}

De acuerdo con la Organización Internacional del Trabajo (OIT, 2001) en los años 1998 y 1999 del total de empleos en hoteles y restaurantes en México el $46 \%$ correspondía a un trabajo no remunerado, es decir, casi la mitad de los empleos. En ese mismo reporte la OIT reconocía una tendencia a contar en estos establecimientos con una plantilla básica de personal y recurrir a contrataciones "atípicas" para una serie de actividades diarias en el turismo, siendo los jóvenes y las mujeres quienes mayormente viven esta situación, además de contar con horarios de trabajo irregulares, falta de pago de horas extra y salarios sin un elemento fijo básico.

Estos señalamientos hechos por la OIT de contratación "atípica" refieren a la subcontratación, outsourcing, o pagadoras, como se les conoce en diferentes regiones, y tienen por objeto la utilización de empresas administradoras de recursos humanos, para prestar sus servicios en una distinta con la que no tienen relación laboral directa, en el caso del turismo, limpieza de hoteles, camaristas, afanadoras y ayudantes en general, entre otros.

En la reforma de la LFT de 2012 se adiciona el artículo 15-A (Cámara de Diputados, 2019) por el cual legaliza la contratación mediada por un contratista (llamadas pagadoras generalmente en turismo) para ejecutar o prestar sus servicios a favor de un contratante, siendo este último el que fija sus tareas y las supervisa, acotando algunos criterios como no abarcar la totalidad de sus actividades, estar debidamente justificado en función a su giro, que de no cumplirse obliga al contratante a ser considerado patrón y asumir todas las obligaciones de la relación laboral.
Sánchezy Olivarría (2016) sostienen que hay ventajas y desventajas de dichas formas de contratación, pues ha tenido el efecto esperado para las empresas y para el trabajador perteneciente a grupos vulnerables (apertura a empleo para jóvenes sin experiencia ni cualificación, así como para mujeres), pero también ha tenido mayores costos en el mercado laboral en general, al desaparecer los contratos, degradarse de las condiciones de sueldos y prestaciones, bajar los costos de contratación y facilitar el despido, dejarlos en la desprotección sindical, y en la pérdida de administración del tiempo.

El personal cualificado en el turismo ha visto transitar sus condiciones laborales en el mismo sentido que el no cualificado, pues para ambos se han establecido esas mismas reglas de operación y administración de sueldos y prestaciones.

Esto confirma lo que Méndez et al. (2013) postulaban al señalar cómo se desarrolla el mercado laboral en México, que sigue los planteamientos de la teoría clásica y no se distingue de otros mercados donde el valor de la fuerza laboral está determinado por su producto marginal.

Así, al no haber un elemento distintivo en cuanto a cualificación en la mano de obra operativa para el turismo y ser esta abundante, pierde valor y es conducida a la precarización.

En la gráfica 5 se muestra la población ocupada que se encuentra en condición de subocupación, es decir, aquellos que laboraron menos de 35 horas por semana, por condiciones de mercado, lo cual significa que, aunque esté dispuesto a destinar mayor tiempo a un trabajo, no lo logra porque el mercado no requiere su fuerza laboral. Los valores corresponden a todas las actividades económicas. 
Gráfica 5. Porcentaje de subempleo con relación a la población ocupada. Se muestran solo los rangos más bajos

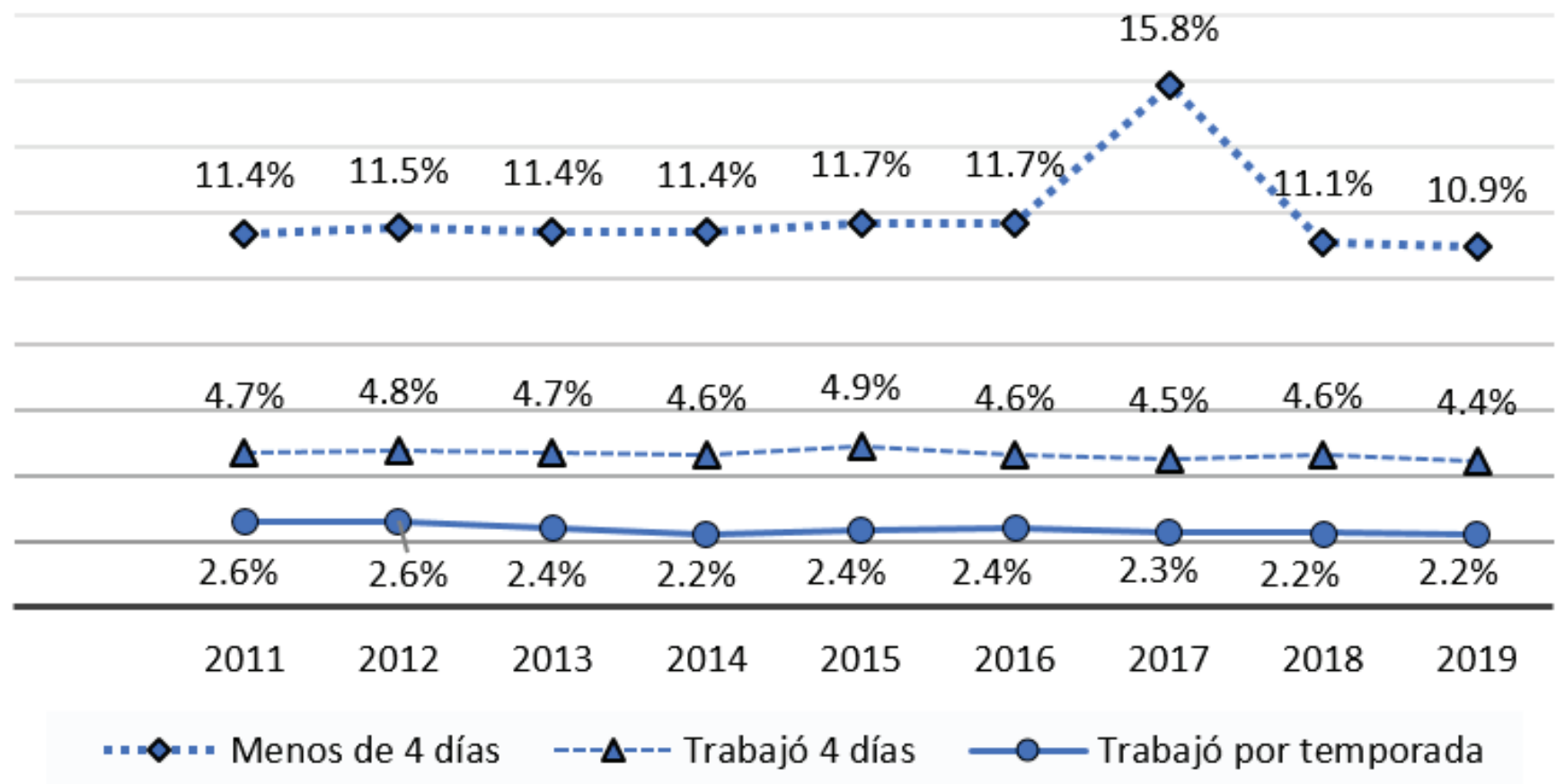

Nota: elaboración propia a partir de los datos de la Encuesta Nacional de Empleo de INEGI (2020).

Como se menciona arriba, el subempleo se considera a partir de que una persona no logra emplearse por más de 35 horas por semana, sin importar los días que destine al trabajo (que incluso puede ser toda la semana).

En la gráfica anterior se muestran solo aquellos casos en los que trabajaron menos de cuatro días, cuatro días y los casos en los que, aunque pudo haber trabajado toda una semana completa, su condición es estacional, en temporadas altas como se conoce en el turismo.

La gráfica muestra que alrededor del $18 \%$ de la población ocupada es subutilizada y que más del $10 \%$ trabaja menos de cuatro días por semana.

Esta condición cada vez más recurrente (ahora de manera legal) en el turismo, donde una proporción de los empleados solo son requeridos los fines de semana, puentes y festivos, que sumado a la depen- dencia que se tiene en algunos centros turísticos del país hace que los esquemas de subcontratación sean ampliamente aceptados, aunque no de agrado.

Este tipo de contratación precariza las condiciones de las personas empleadas bajo este modelo limitando su posibilidad de administración del tiempo pues, en el turismo, se está a disposición de que el contratante decida en qué momento deben presentarse y en qué momento retirarse. Generalmente, los días de trabajo o de descanso se notifican el día anterior, así como los horarios.

El Foro Económico Mundial (WEF por sus siglas en inglés) evalúa entre otros temas el capital humano de cada país y tienen que ver con las condiciones presentes y futuras en indicadores como educación, salud y bienestar (incluido el tema mental), fuerza de trabajo y empleo (experiencia, talento, de la fuerza de trabajo), y condiciones del entorno para trabajar (WEF, 2013). 
De acuerdo con este reporte, México ha transitado de la posición 58 que ocupó en 2013 al 69 en 2017 (más reciente publicación) (WEF, 2017), es decir, lejos de que las políticas y los cambios en la LFT hayan servido para un desarrollo del capital humano, se ha transitado en el sentido contrario, hacia su precarización.

\section{Metodología}

Para el logro del objetivo planteado, de analizar las condiciones laborales en las que se encontraba el personal empleado en el turismo y tener un panorama de lo que se enfrentará al irse reactivando la actividad después de la contingencia sanitaria, así como los efectos de la pandemia en los sectores de la población de este mismo grupo, se diseñó un cuestionario siguiendo las categorías en torno a la precarización y tipo de contrato.

La recopilación de información, por cuestiones del confinamiento, se llevó a cabo de forma electrónica utilizando la plataforma llamada encuestafacil.com.

Se distribuyó mediante grupos de profesionales de turismo en la red social Facebook; mediante perfiles de seguidores de las cuentas oficiales de Twitter de turismo a nivel federal, estatal, municipal y de destino, así como de cuentas de empresas y organizaciones dedicadas al turismo.

Así mismo, se aprovecharon los "Hashtags" que hacen referencia al turismo y su reactivación, priorización y los distintos webinars que se han promovido en las mismas redes, considerando que el trabajador del turismo estará pendiente de esos eventos y compartirá las temáticas que son relevantes para la actividad.

El criterio empleado para la selección de los perfiles a quienes enviar el cuestionario fue que el usuario hiciera referencia a dedicarse al turismo, que la ubicación de la cuenta señalara como ubicación México y que la misma mostrara actividad reciente.
De esta forma, se logró hacer llegar el cuestionario a más de dos mil personas (aquellos que recibieron y abrieron el link para conocer de qué se trataba) logrando una respuesta positiva de 434 personas, lo que puede considerarse representativo, pues para poblaciones infinitas una muestra de 385 individuos es suficiente, con un nivel de confianza de $95 \%$ y margen de error de $5 \%$. La recopilación de información inició el 26 de mayo y concluyó el 15 de junio del presente. La contingencia con la indicación de las autoridades con la exhortación a detener actividades consideradas como no esenciales se dio el 20 de marzo.

El cuestionario iniciaba con datos de identificación y el tercer ítem hacía referencia a su condición laboral en el turismo al inicio de la contingencia, de tal forma que se utilizó como filtro para que solo desplegara el resto de las preguntas aquellas que se encontraban laborando al inicio de la misma.

El diseño de la plataforma se codificó de tal forma que no permitió la respuesta doble desde un mismo dispositivo.

\section{Resultados}

A continuación, se presentan los resultados obtenidos de la aplicación del cuestionario, el cual se divide en dos partes, la primera de manera descriptiva, que brindará un panorama general de la composición de la muestra, y una segunda, que de manera más específica analiza los resultados por grupo de interés.

\section{Descripción de la muestra}

Las respuestas que se obtuvieron corresponden en un $52 \%$ al sexo masculino y un $48 \%$ al sexo femenino, es decir, no hay una diferenciación sustancial entre ambos.

Con relación a la edad, el $51 \%$ de los encuestados tienen más de 35 años de edad, el $18 \%$ tiene entre 30 y 35 años. Un $15 \%$ tiene entre 20 y 25 años y 
esa misma proporción la tienen aquellos cuya edad oscila entre 25 y 30 ańos de edad. Solo el $1 \%$ es menor de 20.

En cuanto a la industria en la que se encontraban empleados los encuestados al momento de iniciar la contingencia sanitaria, el $27 \%$ lo hacía en agencias y operadoras de viajes, un $19 \%$ en hotelería, un $12 \%$ se empleaba como guías, $11 \%$ en entretenimiento para el turismo, $8 \%$ en transportación, $6 \%$ en AyB y solo un $2 \%$ de las respuestas que se obtuvieron corresponden a quienes se empleaban en la comercialización de artesanías, tal y como se muestra en la gráfica 6 .

Gráfica 6. Distribución de la industria en la que se encontraba empleado al iniciarse la contingencia

\section{¿En qué industria se encontraba el empleado al iniciar la contingencia?}

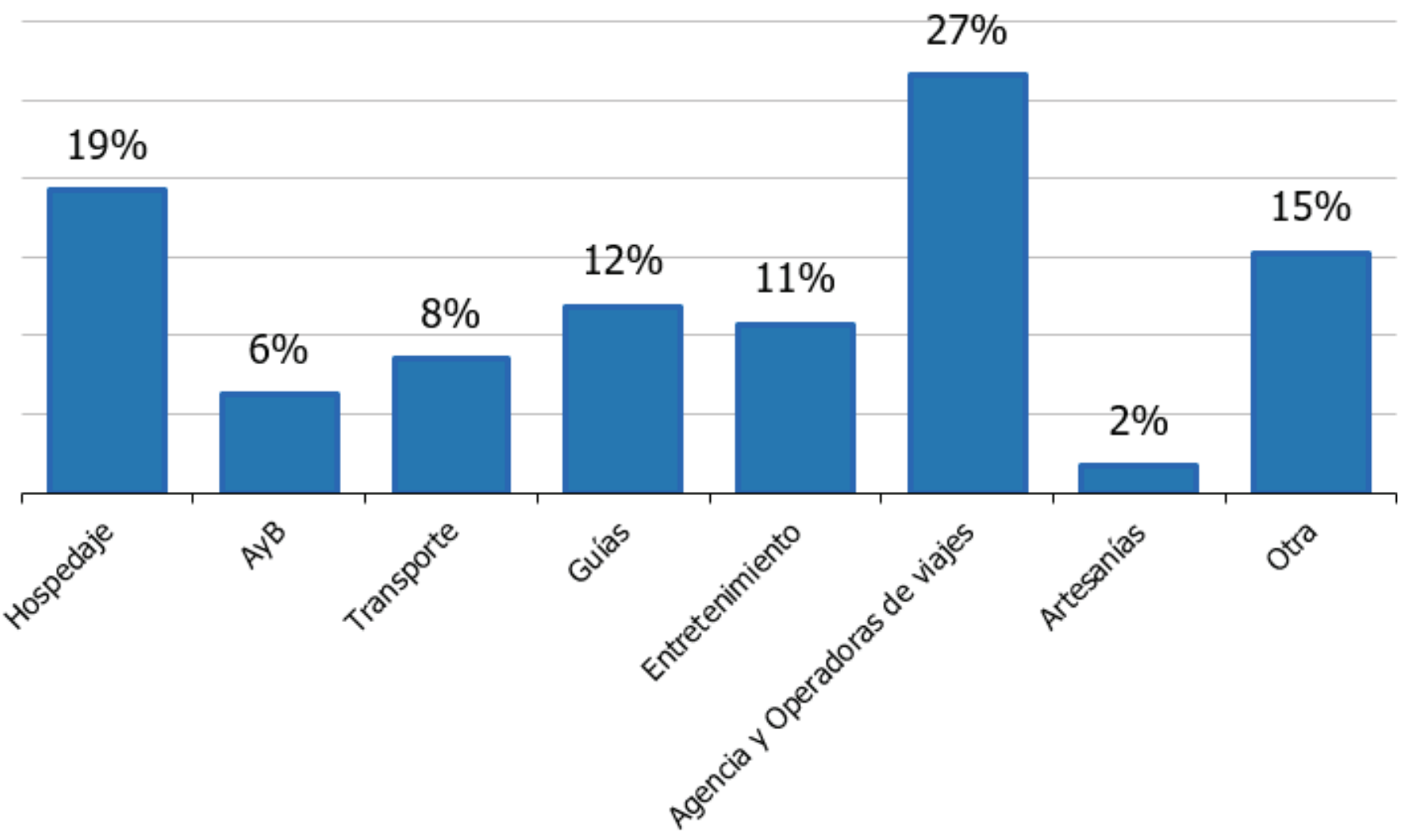

En lo que corresponde a la forma de contratación de los encuestados se obtuvo que el $48 \%$ de los mismos tenía una relación formal definitiva, de planta como también se le conoce, mientras que un $25 \%$ se encontraba en el autoempleo, $9 \%$ con un contrato temporal y esa misma proporción como comisionista, $8 \%$ con una relación laboral mediada por Outsourcing o Pagadoras y solo el $1 \%$ sin contrato, sino solo con ingresos vía propinas, como se puede ver en la gráfica 7 . 
Gráfica 7. Condición laboral del empleado inicio de la contingencia por Covid-19

\section{Condición laboral que tiene al inicio de la contingencia}

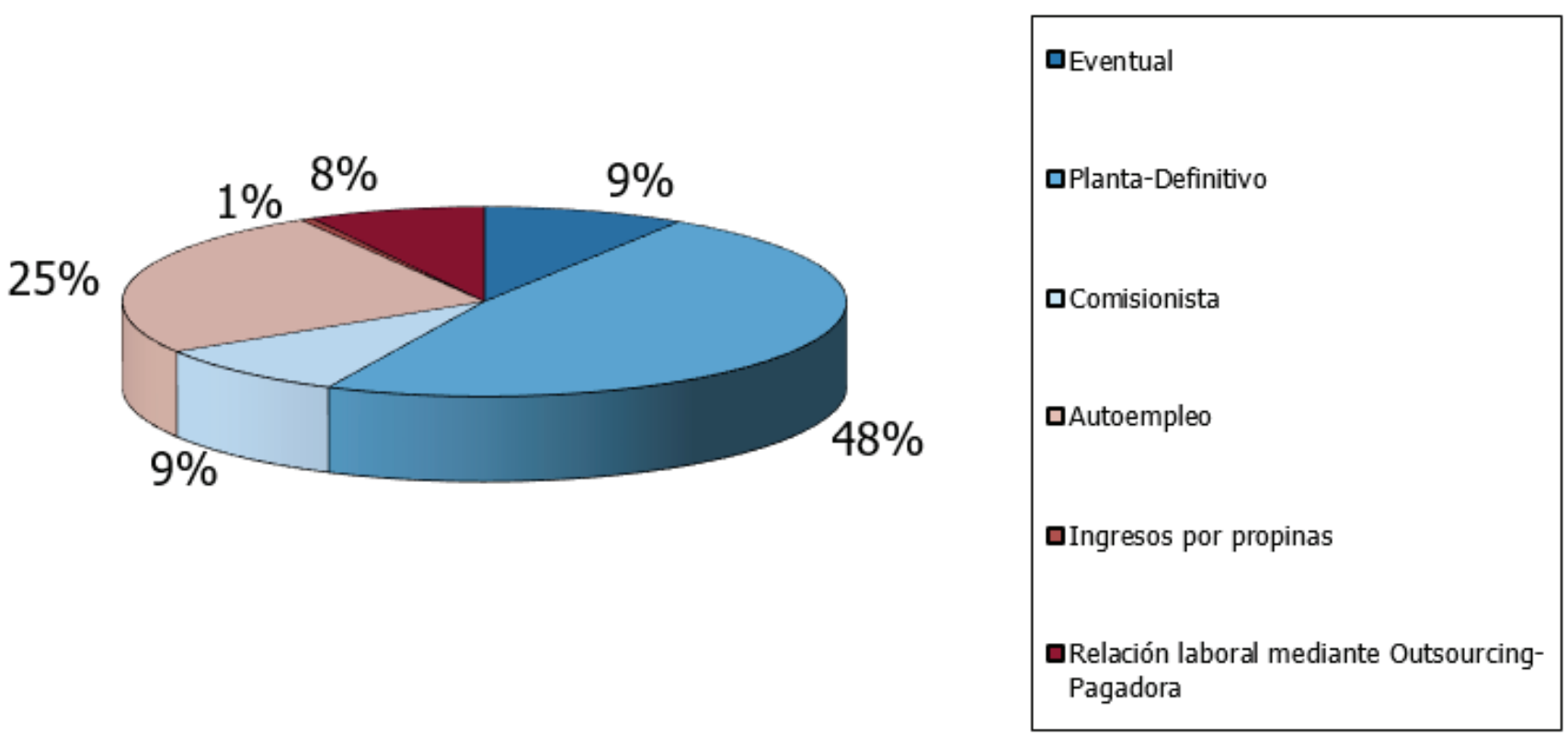

En cuanto al tiempo que tenían de relación laboral, el $35 \%$ tenía más de 6 años laborando, el $24 \%$ entre 6 meses y 2 años, $16 \%$ más de 2 años y hasta de 4, $12 \%$ más de 4 y hasta 6 años, así como la misma proporción de $12 \%$ con menos de 6 meses, es decir, de reciente ingreso.

El $69 \%$ de los encuestados refiere tener estudios profesionales como máximo grado de estudios, $14 \%$ cuenta con posgrado, $10 \%$ tiene bachillerato y $6 \%$ reporta tener estudios técnicos; mientras que solo un $2 \%$ tiene estudios máximos de secundaria.

Con relación a la posición jerárquica del puesto ocupado que tenían al momento de iniciar la contingencia, los resultados obtenidos se aprecian en la gráfica 8 , como se muestra a continuación. 
Gráfica 8. Puesto ocupado al inicio de la contingencia

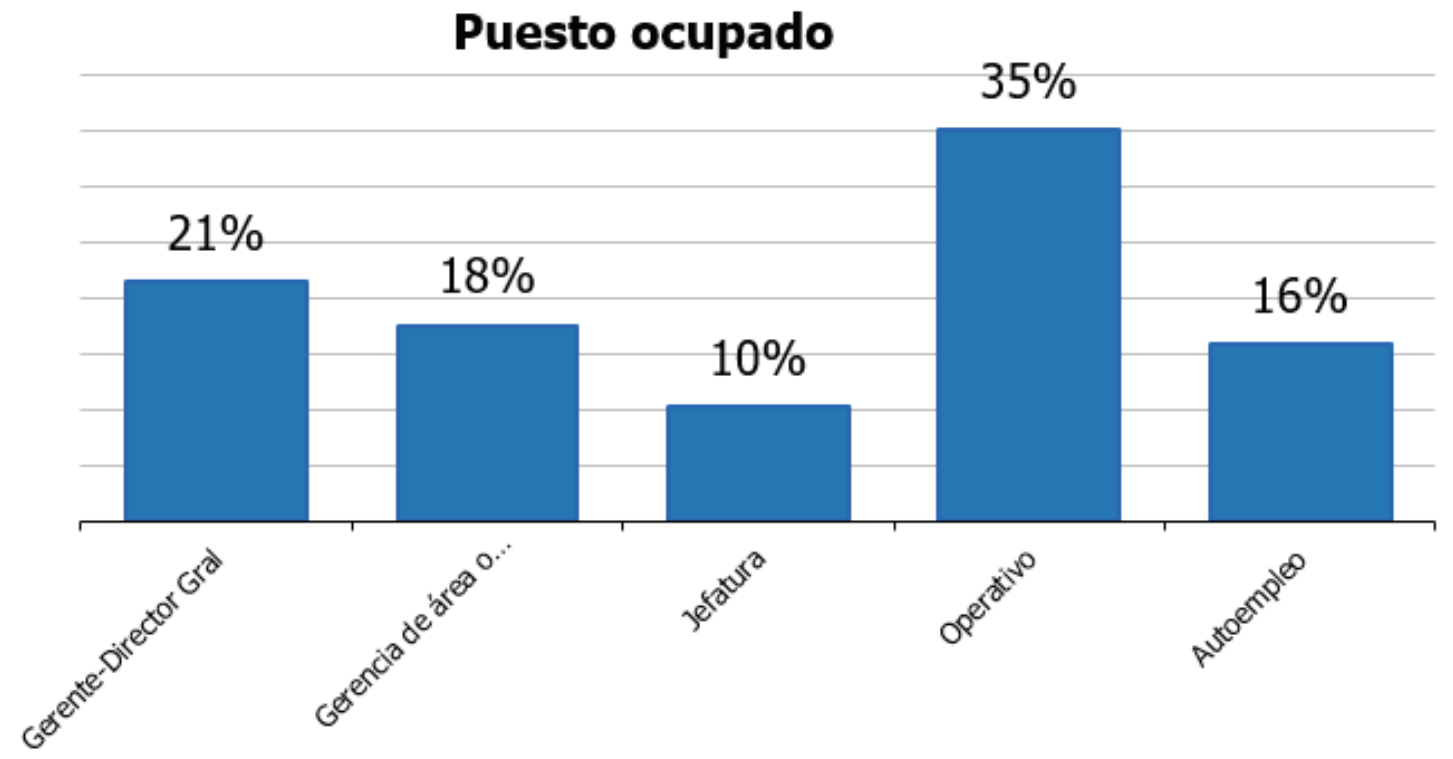

La mayor parte de los encuestados se empleaban en funciones operativas con un $35 \%$, seguido de aquellos que ocupaban una posición de gerencia general $(21 \%)$ o gerencia de departamento $(18 \%)$. Un $16 \%$ de los encuestados se considera como autoempleados y un $10 \%$ ocupaba una plaza a nivel jefatura.

El $82 \%$ de los encuestados considera que las condiciones laborales hasta el inicio de la contingencia eran

Gráfica 9. Razón por la cual califica como tales sus condiciones laborales

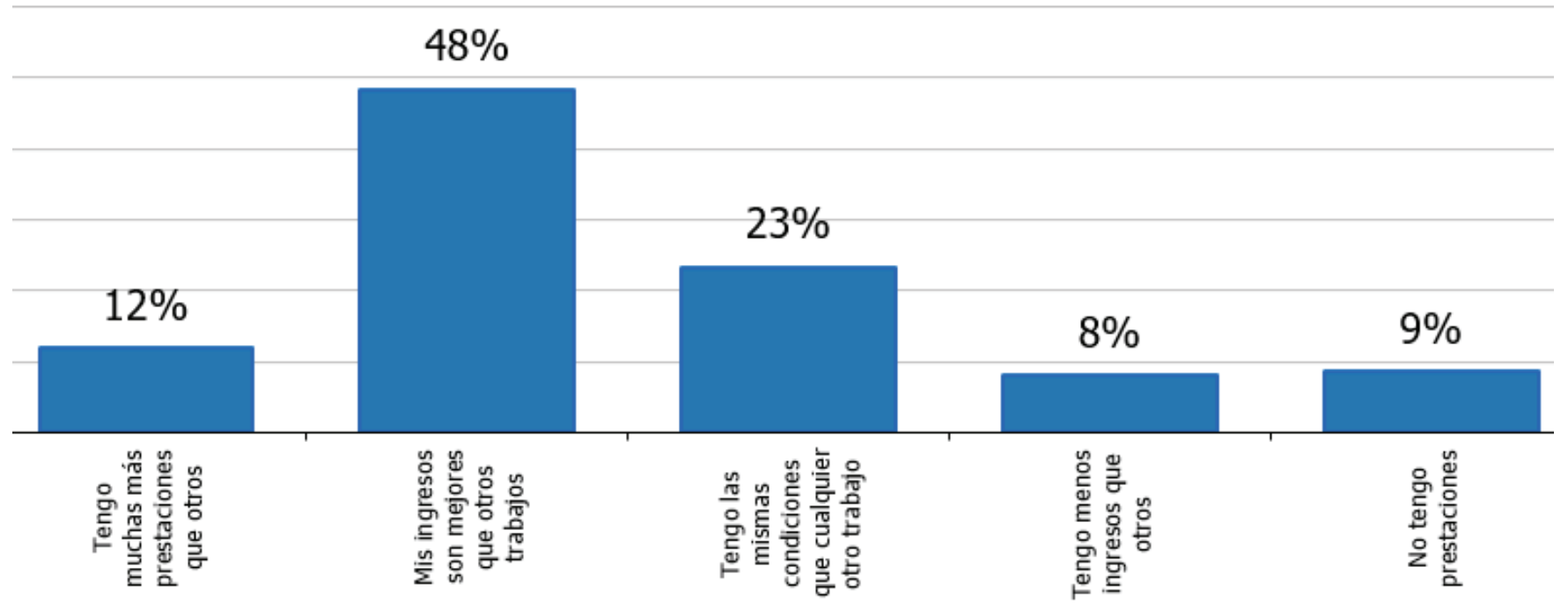


El $48 \%$ de los encuestados valora sus condiciones laborales en función de percibir mayores ingresos que otros trabajos, mientras que $12 \%$ de ellos considera que tiene más prestaciones. El $23 \%$ de los encuestados responde que tiene las mismas condiciones de trabajo.

En el lado opuesto, el $8 \%$ menciona percibir menores ingresos que otros trabajos, mientras que el $9 \%$ considera que sus condiciones laborales no son buenas por no tener prestaciones.

Aunque la contingencia inició en México a partir del 20 de marzo, (casi dos meses antes de la recopilación de la información) se preguntó a los encuestados sobre las medidas tomadas por la empresa en donde trabajaban al inicio de la misma, pues de manera paulatina, prácticamente todas las actividades relacionadas con el turismo se suspendieron, por lo en el sentido de la pregunta se obtuvo que el $54 \%$ de los encuestados respondieron que su empresa cerró totalmente, un $29 \%$ no cerró y continuó con sus operaciones al inicio de la contingencia, mientras que un $17 \%$ restante trabajaban dos, tres días a la semana o solo fines de semana.

La consecuencia de las medidas anteriores ocasionó diferentes situaciones. En la gráfica 10 se muestran los resultados de la encuesta.

Gráfica 10. Consecuencia de las medidas de aislamiento y confinamiento

\section{¿Cuáles fueron las consecuencias de las medidas de aislamiento y confinamiento por la contingencia?}

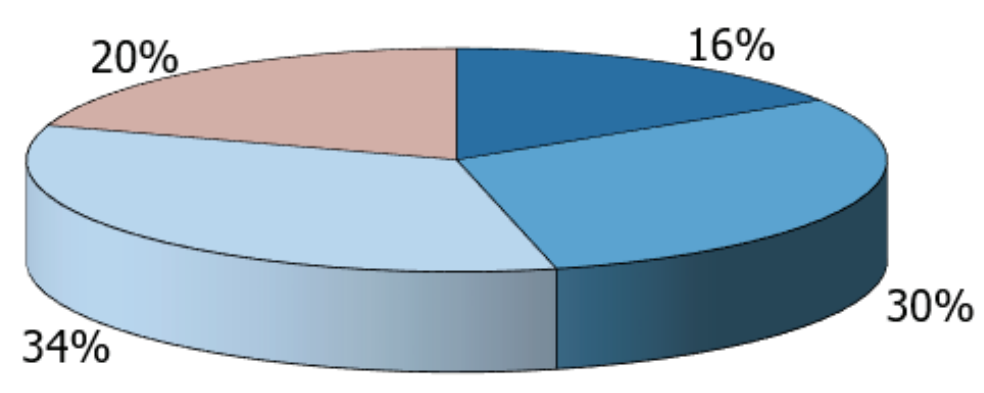

口Mantuve mi empleo y mis ingresos

口Mantuve mi empleo pero disminuyeron mis ingresos (descanso sin goce/ incluye días solidarios)

口Disminuyeron mis ingresos por depender de mis ventas/propinas (autoempleo)

口Perdími trabajo

El $20 \%$ de los encuestados perdieron su empleo, un $34 \%$ más disminuyeron sus ingresos al depender de las ventas (incluye comisionistas) o por ser autoempleados. El $46 \%$ de los encuestados declara haber mantenido su empleo y solo el $16 \%$ del total mantuvo su empleo y sus ingresos.

Finalmente, un $5 \%$ de los encuestados reporta haber sufrido discriminación laboral, identificando que el pertenecer al grupo de mayor edad y con algunas enfermedades crónicas degenerativas fue el motivo de sufrirla.

De manera general, en la pregunta relativa a las preferencias de los encuestados con relación a la etapa post Covid-19, se encuentra que un $45 \%$ de ellos considera que la situación que se vive por esta condición, que afecta las actividades cotidianas 
y el turismo como fuente de ingreso, forman parte del riesgo y que se mantendrán en las condiciones en las que se desempeñaban al inicio de la misma.

Un $19 \%$ de los encuestados considera que una opción sería que el gobierno les retuviera una parte de sus ingresos para crear un seguro de empleo, para ser utilizado en situaciones como la presente. En contraste, el $11 \%$ considera que ese tipo de seguros tendría que ser por iniciativa propia con una aseguradora privada.

El $13 \%$ de los encuestados buscaría colocarse en una empresa que sea más solidaria ante este tipo de contingencias, y el $12 \%$ de los encuestados consideraría cambiar de actividad económica, por las condiciones por las que pasa.

\section{Análisis de los resultados}

Para dar respuesta al objetivo perseguido por este trabajo, se analizaron distintas combinaciones sobre algunos de los grupos de interés, de los cuales se ha mencionado padecen las consecuencias de las reformas en materia laboral.

Un grupo considerado vulnerable ante tal situación está compuesto por las mujeres, ya que del total de respuestas obtenidas se desprende que un $49 \%$ de ellas tenían una relación laboral estable, es decir, se esperaría que, aunque hayan detenido sus actividades por la pandemia, al cambiar las normas sanitarias dictadas por las autoridades gubernamentales se iniciaría la recuperación económica y conservarían las mismas en las condiciones contractuales que gozaban antes de la contingencia

En ese sentido, el $51 \%$ de las mujeres empleadas en la industria turística sí se encuentran en alguna situación de riesgo para obtener su fuente de ingresos, es así que el $9 \%$ mantiene una relación laboral poco estable, ya que han sido contratadas por una empresa de Outsourcing o Pagadora, y un $8 \%$ en una relación laboral por tiempo determinado. Es decir, hay un
$17 \%$ de mujeres cuya relación laboral es precaria ya que, durante la crisis sanitaria, el criterio que rige es la solvencia económica de la empresa.

El autoempleo es una manera de generar ingresos propios, es así que el $33 \%$ de las mujeres encuestadas se encuentra en esta condición, dentro del porcentaje ya mencionado, destaca con un $8 \%$ de quienes trabajan únicamente por comisión en este sector, viendo disminuidos sus ingresos ya que están íntimamente asociados al descenso de la actividad turística en el país.

El $78 \%$ de los encuestados consideraban que su relación laboral era buena o muy buena ya que al momento de realizar el estudio la actividad turística ofrecía mejores ingresos que en otras, sin embargo, casi la mitad (36 \%) manifiesta que la suspensión de la actividad turística es un riesgo propio de este ramo.

El $8 \%$ de las mujeres considera cambiar de actividad económica como opción para evitar las afectaciones que se presentan y afectan al turismo.

El segundo subgrupo de interés lo conforman los jóvenes. Si se considera solo aquellos menores de 25 años, equivale al $16 \%$ de la población encuestada. De este subgrupo el $61 \%$ son mujeres y el resto son hombres.

El $50 \%$ de los menores de 25 años tenían ya una relación laboral definitiva, por lo que, en el momento de retomar actividades en el turismo, se esperaría que se reincorporaran a sus empleos.

En este subgrupo, es más amplio el porcentaje de aquellos que se encuentran en situación vulnerable debido a la modalidad de su empleo, pues el $29 \%$ de ellos contaba con un contrato temporal y el $11 \%$ en una relación mediada por Outsourcing o Pagadora. Es decir, que el $40 \%$ de jóvenes que se empleaban en el turismo al momento de iniciarse la contingencia sanitaria, están en una situación de perder su fuente de empleo. 
Cabe destacar que en el grupo de jóvenes el $77 \%$ tenía una antigüedad laboral no mayor a dos años, lo que implica no contar con estabilidad laboral ni los beneficios que aportan pertenecer a una empresa en que ha prestado sus servicios de forma continua por más tiempo.

Aún con lo antes dicho, el $75 \%$ de este subgrupo consideraba su relación laboral como buena y muy buena, y solo un $25 \%$ la consideraba como regular. La principal razón de lo anterior está dada nuevamente con aquella que hace referencia a tener mejores ingresos que en otros empleos, en el mismo porcentaje $(36 \%)$ de quienes consideran que sus condiciones son iguales a otros empleos y un $11 \%$ que dice tener más prestaciones que en otros empleos.

Solo un $7 \%$ de este subgrupo prefiere buscar empleo en otra actividad económica como medida para evitar las distintas contingencias que afectan al turismo, mientras que el $36 \%$ considera que eso es parte del riesgo de la actividad turística.

Otros de los resultados que se han encontrado es analizar las condiciones de aquellos que califican sus condiciones laborales como buenas o muy buenas, ya que el $82 \%$ de las respuestas obtenidas fueron en estos dos rubros.

No existe una marcada diferencia en el sexo de quienes así respondieron, aunque quienes conforman este grupo en su mayoría (51\%) tienen más de 35 años y el $50 \%$ de ellos tiene una relación laboral "de planta" principalmente en agencia y operadora de viaje $(27 \%)$ y hoteles $(21 \%)$, seguido de un $23 \%$ que se auto emplea. Destaca que la formación de este grupo es alcanza un nivel profesional (67\%) y el $70 \%$ de ellos considera que su relación laboral es buena o muy buena debido a que tiene mejores ingresos que otros trabajos ( $56 \%$ ) o sus prestaciones son mejores que otros empleos (14\%) y que la situación actual es parte de los riesgos implícitos en la actividad (49\%), por lo que no planean un cambio en las condiciones actuales de trabajo.
Como se mencionó arriba solo el $1 \%$ consideró sus condiciones laborales como malas o muy malas, por lo que es poco lo que se puede extraer más de información de ese grupo.

El sector turístico se ha caracterizado por una gran rotación de ciertos puestos generalmente en las áreas operativas, es así que el $39 \%$ de los encuestados tenían una antigüedad no mayor a seis meses en su puesto.

Debido a los resultados arrojados, se puede mencionar que el empresario turístico, además de cuidar la salud del turista, debe poner especial cuidado en el bienestar de sus empleados y realizar esfuerzos para preservar el empleo.

Por otra parte, y reconociendo que el escenario económico es muy complejo en la actualidad como resultado de las pérdidas cuantiosas que sufrieron las empresas turísticas, obliga a que los empresarios deban plantear estrategias de máxima flexibilidad para evitar afectaciones adicionales a sus trabajadores.

Siguiendo en la misma línea, la actividad turística aporta un carácter dinamizador a la economía, por lo tanto, se requiere de apoyos extraordinarios conjuntamente con políticas federales que el gobierno pueda poner en marcha, para reactivar el sector turístico a nivel nacional.

\section{Conclusiones}

Las condiciones laborales en el tema de la legislación sí favorecen abiertamente la subcontratación y la flexibilidad de la jornada laboral en el turismo, como en otras industrias, sin embargo, en línea con los resultados mostrados, son los empleados operativos quienes se ven más afectados por dichas condiciones, pues la menor proporción la componen quienes tienen un contrato temporal o mediado por una pagadora.

De forma similar, la precarización laboral afecta a quienes tienen una formación profesional menor o 
carece de ella, privilegiando a quienes en el transcurso de su carrera laboral van especializándose en sus labores u optando por hacerlo mediante estudios profesionales y de posgrado.

Esta situación se repite con los dos grupos considerados vulnerables en el turismo: las mujeres y los jóvenes, pues en ambos casos la mitad de ellos tienen una relación laboral estable y directa con la empresa donde prestan sus servicios, no mediante pagadoras.

Lo anterior, puede considerarse desde dos perspectivas opuestas: las condiciones laborales en el turismo no favorecen a los segmentos de la población menos favorecidos en formación en general y específica para la industria, o bien, privilegia la especialización y profesionalización del empleo, pues cerca del $80 \%$ de quienes trabajan en el turismo considera obtener mejores ingresos o mejores prestaciones que otras industrias.

Es decir, el empleado que por necesidad ha llegado a trabajar al turismo sin una formación y se encuentra en una condición precaria, podría padecerla en cualquier otra industria. Pero quien se forma y especializa para el turismo, obtiene los beneficios de ese esfuerzo por su formación.

Esa parte de empleados regresará a sus actividades en tanto se vaya recuperando la actividad turística y en función a ello, recuperará sus ingresos y beneficios anteriores.

Un tema que sale a la luz del presente trabajo tiene que ver con aquellos quienes se forman o tienen por objetivo formarse profesionalmente para el turismo.

La investigación refleja que quienes actualmente lo hacen, saben que, para obtener los beneficios de la actividad, como ya se dijo, principalmente se dan en ingresos más altos que otras industrias, tienen que buscar la especialización y profesionalización en la actividad. Pero también, el hecho de que consideren la contingencia como parte del riesgo que se enfrenta revela un perfil sobre las cualidades necesarias para quien elige esta actividad como su principal fuente de ingresos. La mayor parte de quienes trabajaban en el turismo no se victimizan ante la situación, sino que la afrontan como parte del riesgo profesional.

Finalmente, es de considerarse tanto por empleados como por empleadores, que existe un $30 \%$ de personas dispuestas a laborar con un seguro que les aporte los ingresos en casos de contingencia, ya sea de manera privada o pública, para hacer frente a situaciones como la actual que merma sus ingresos. $\mathrm{Si}$ bien, por el lado del sector público, correspondería a la Secretaría del Trabajo, resulta interesante saber qué pasa si se incluye como parte de la Responsabilidad Social Empresarial. Es decir, si empresas turísticas pretenden distinguirse y retener el talento humano, podría ser esta una alternativa para lograrlo.

Futuras líneas de investigación pueden desprenderse en torno a los análisis cuantitativos sobre las condiciones (ingresos, prestaciones, etc.) entre empresas de distintas ramas en destinos turísticos, que muestren si se trata de diferencias sustanciales en cuanto a las mismas, o solo se basan en la percepción de quienes laboran en ellas.

Una más está dada por el análisis del perfil profesional de quienes logran obtener posiciones destacadas y mejores ingresos, para identificar su existen cualidades en ellos que les facilite el acceso a los mismos, como parte de definición de los perfiles deseados en las instituciones encargadas de su formación. 


\section{Referencias}

Brida, J. G., London, S., \& Rojas, M. (2014). El turismo como fuente de crecimiento económico: Impacto de las preferencias intertemporales de los agentes. Investigación Económica, 73(289), 59-77. https://doi.org/10.1016/ S0185-1667(15)30003-5

Cámara de Diputados. Ley Federal del Trabajo, DOF \$ (2019). http://www.diputados.gob. mx/LeyesBiblio/pdf/125_020719.pdf

Cañada, E. \& Izcara, C. (2021). Precariedad laboral y viviendas de uso turístico. Alertas para una reactivación pospandemia. Alba Sud. 56 p.

Consejo Nacional Empresarial Turístico, CNET. (2020). Noticias relevantes sobre el turismo mexicano. Retrieved May 29, 2020, from https://www.cnet.org.mx/

Datatur-Sectur. (2020). Empleo turístico. Retrieved September 10, 2020, from https://www. datatur.sectur.gob.mx/SitePages/ResultadosITET.aspx

Hosteltur. (2018, May 24). Sólo el 25 \% de mujeres tienen posición de liderazgo en el sector turístico. Hosteltur. Retrieved September 10, 2020, from https://www.hosteltur.com/ comunidad/nota/022143_solo-el-25-demujeres-tienen-posicion-de-liderazgo-en-elsector-turistico.html

Instituto Nacional de Estadística y Geografía, INEGI. (2019, December 18). Turismo. Retrieved April 16, 2020, from https://www.inegi.org. $\mathrm{mx} /$ temas/turismosat/

Instituto Nacional de Estadística y Geografía, INEGI. (2020a). Resultados de la Encuesta Telefónica de Ocupación y Empleo (ETOE). México.

Instituto Nacional de Estadística y Geografía, INEGI. (2020b, March). Empleo y Ocupación. Retrieved May 28, 2020, from https://www. inegi.org.mx/temas/empleo/
Méndez, C., Rodríguez, O., Osorio, M., \& Salgado, C. (2013). La flexibilidad laboral en el sector turístico en México. Estudios y Perspectivas En Turismo, 22(4), 705-728.

Montiel-Flores, J. (2020). Alternativas orientadas al rescate del turismo en México en el contexto del COVID-19. Revista Sinergia, 1(7), 41-61.

Organización Mundial del Turismo, OMT. (2020). Barómetro del Turismo Mundial. Barómetro OMT del Turismo Mundial mayo 2020 con especial enfoque en el impacto de la COVID-19 (resumen) (Vol. 19). https://doi. org/10.18111/9789284421831

Organización Internacional del Trabajo. (2001). El desarrollo de los recursos humanos, empleo y la mundialización en el sector de la hotelería, la restauración y el turismo. Ginebra.

Palafox-Muñoz, A. y Rubí-González, F. A. (2020). La gota que derramó el vaso en el turismo en Quintana Roo, México: precariedad laboral y COVID-19. Dimensiones Turísticas, 4(Número especial: Turismo y COVID-19) 131-148.

Presidencia de la República. (2013). Plan Nacional de Desarrollo 2013-2018. Retrieved February 17, 2016, from http://www.dof.gob.mx/ nota_detalle.php?codigo $=5299465 \& \mathrm{fecha}=$ 20/05/2013

Rubí-González, F., \& Palafox-Muñoz, A. (2017). El turismo como catalizador de la pobreza. Alba Sud Editorial.

Rubio Campos, Jesús (2017). Sindicalización y precariedad laboral en México. Región y Sociedad, XXIX (68), 37-75.

Sánchez, V., \& Olivarría, C. (2016). Desafíos y derroteros de los estudios laborales de turismo México: El tema de la flexibilidad laboral. Revista Latino-Americana de Turismologia, 2(2), 49-58. 
Sectur-Datatur. (2020). Atlas Turistico de México. Retrieved July 1, 2020, from https://www. atlasturistico.sectur.gob.mx/AtlasTuristico/ bienvenido.do\#

Secretaría de Turismo, Sectur. (2018). Datatur3 - RankingOMT. Retrieved April 16, 2019, from https://www.datatur.sectur.gob.mx/SitePages/RankingOMT.aspx

Secretaría de Turismo, Sectur. (2020). Resultados de la Actividad Turistica Enero 2020. Retrieved April 16, 2020, from https://datatur.sectur. gob.mx/RAT/RAT-2020-01(ES).pdf

United Nations World Tourism Organization, UNWTO. (2019). Panorama del turismo internacional. Madrid. https://doi.org/10. 18111/9789284421237

United Nations World Tourism Organization, UNWTO. (2020, April 1). Launches a call for action for Tourism's COVID-19 mitigation and recovery. Retrieved June 1, 2020, from https:// www.unwto.org/news/unwto-launches-a-callfor-action-for-tourisms-covid-19-mitigationand-recovery
World Economic Forum, WEF. (2013). The human capital report. Cologny/Geneva Switzerland: World Economic Forum.

World Economic Forum, WEF. (2017). The Global Human Capital Report 2017. Retrieved May 29, 2020, from https://www.weforum.org/ reports/the-global-human-capital-report-2017

World Travel \& Tourism Council, WTTC. (2020, March). Economic Impact Reports. Retrieved June 4, 2020, from https://sp.wttc.org/ Research/Economic-Impact 